\title{
Perception of University Students on Gender Issues in the Industry
}

\author{
Subashini Suresh ${ }^{1}$, Amal Hj Abdul Aziz ${ }^{1}$, Mark Stride ${ }^{2}$, Suresh Renukappa ${ }^{1}$ and \\ Paul Hampton ${ }^{1}$. \\ ${ }^{1}$ University of Wolverhampton, Wolverhampton, WV11LY and ${ }^{2}$ Orbit Group, \\ Coventry, CV39NB, UK \\ s.subashini@wlv.ac.uk
}

\begin{abstract}
The UK construction industry is currently suffering from a skills shortage. There are many reasons and issues that surround this, however Office of National Statistics data shows only $13 \%$ of the construction industry is employed by females. This research study will discuss the perception of the construction industry by students studying construction subjects. The research within this study involved literature review and 12 qualitative interviews. The results revealed that there are campaigns to encourage women to join the constructions industry however there is still a stigma attached that the industry is scarred by discrimination, harassment, pay equality and stereo typing that are deterring females from offering greater diversity, new ideas and a solution to the skills shortage from joining the industry. On this basis, a culture change and new legislation clearing up the major issues within the construction industry needs to be completed prior to remarketing the image of the industry campaigning enabling females to join the sector.
\end{abstract}

Keywords: Discrimination, harassment, gender, skill shortage

\section{Introduction}

The construction industry is currently battling with a shortage of skilled tradesmen and professionals - many of the current workers are aging and young adults are not interested in joining the sector. Schouten (2017) explains there are a total of 27 million people employed within the UK, with an approximate 50:50 split between both genders. The construction industry employs 2.3 million workers, however the Office of National Statistics (ONS, 2018) understand that only 13\% are female, displaying a large unbalance. According to the Construction Industry Training Board (CITB, 2019) the construction industry will need to recruit a further 157,000 people to keep up with the demand of the sector by 2021. The aim of this study is to review what the limitations and perception barriers that stop women joining the construction industry, but also to raise awareness of the shortage and the benefits of the built environment from a student's perception.

The main objectives within this study are to;

- $\quad$ investigate what the industry is already doing to help reduce the skills shortage, 
- understand what the students perception of construction sector is,

- discover what the limitations are for women within the construction industry.

- how to overcome the limitations for females in the construction industry

By following these objectives it enabled the researcher to find an adequate method to encourage women to join the industry. To complete this study, a literature review has been undertaken to find out what research has already been carried out. This was continued by carrying out a qualitative assessment of student's perception of their education and the industry.

\section{Literature Review}

Grant Prior from Construction Enquirer (2019) stated that a further 168,500 construction related jobs will become available over the next five years despite the uncertainty of Brexit. However as the job opportunities continue to rise, this causes the shortage in workers to increase also, therefore there must be an increase in methods taken to fill the skills deficit. We know that there are many opportunities for females to join the industry; however are they aware of them?

\subsection{Skills shortages and its impact}

The last recession caused a huge decline in employment within the construction industry; the CITB explained that the total construction output hit an all-time low in 2009, and therefore forced many construction workers to leave the industry. The CITB (2018) explained that these workers have never been replaced and has left a shortfall within a booming market. Due to the small workforce within the construction industry, it has proven difficult for employers to recruit. Therefore one of the incentives to entice applicants is an increase in salaries. Dominic Claeys-Jackson from Prospects (2017) and Construction Enquirer (2016) reported that salaries had increased by $6 \%$, a rate three times larger than across other industries. Brian Berry, Chief Executive of the Federation of Master Builders (FMB) (2018) also explained that 'two-thirds of those running small and medium-sized construction firms are struggling to hire bricklayers and carpenters as construction skills shortages hit a record high'. Brexit has left many employers and employees with doubts over their job security, and this could prove to have a huge impact. Jodie Cox from the Independent (2017) reported that 176,500 European workers are employed within the industry, meaning that a huge vacuum could be left if they are forced to leave the country. The industry is also battling against an aging workforce. In 2013 the CITB announced that over 400,000 people were expected to leave the industry within the next 5-10 years and the rate of recruitment is not matching the amount of workers retiring. Radford (2017) explained that due to the age of the workforce many tradesmen are retiring from the industry and are not being replaced. RICS Chief Economist, Rubinsohn (2016) also explained that the labour shortages in the construction sector are causing significant delays at various stages of the construction process and cannot keep up with the demand of building 110,000 houses per year. Therefore the construction industry cannot build enough properties to house the expanding population (The Construction Index, 2016). Millennials are having a huge 
impact on the construction industry, due to them not wanting to join the sector. Neil Martin of Lend Lease (2016) describes that the industry is poorly communicating with young adults and not describing what there is to offer and what career opportunities are available, therefore the workforce will reduce until this issue is corrected. Hilary Osbourne (2016) from The Guardian explained that the impact of the skills shortage covers issues such as the housing programme, salary inflation and a smaller workforce. Due to the construction industry demanding more progress with building projects but having a limited workforce available, construction companies are battling for tradesmen and professionals, enabling employees to have higher salary expectations.

\subsection{Obstructions stopping females joining the industry and the benefits of joining the industry}

There are many advantages for women to join the construction industry such as diversity, skills shortages, team work and to satisfy the growing population, however equally there are also negatives that stop females joining the sector such as harassment and discrimination, stereotyping, their family commitments, a lack of opportunity and awareness.

Matthew Goff (2019), Director of UK operations at Actavo Building Solutions, explains that having a diverse workforce can achieve better results across the business. HHe furthered this by stating that within the sector there is a huge gender pay gap of almost $45.5 \%$ and that if an individual is capable of undertaking a task regardless of their age, gender, ethnicity, sexual orientation or physical impairment they should have the opportunity to do so. The Royal Institute of Chartered Surveyors (RICS) (2018) explain by encouraging a more diverse workplace, it helps inspire more people to join the industry as it will complement the individuals personalities enabling more personnel to review projects increasing the team work and satisfying the skills deficit. However unfortunately there are several negatives that must be addressed that are currently deterring females and students from joining the construction industry. Kimberle Crenshaw (2016) claims there must be support against intersectionality within the workplace as she believes that multiple factors such as gender, religion, ability and race discrimination is stopping the public from joining industries and employers are discriminating against potential employees. She also believes that white women are traditionally employed to complete administration positions and white men would complete the manual jobs. Using this analogy it suggests that women cannot complete the manual or professional positions and RG Group (2017) confirm this by claiming that the stereotype that men are physically bigger and stronger deters females from joining the industry and get drawn to other sectors. RG Group furthered this by explaining that the perception of the construction industry is that it is male dominated and therefore when women join the industry they feel they might be treated differently, thus keeping their heads down and acting as 'one of the lads'. This view enhances the evidence that the construction industry is poorly marketed - not only is it perceived to be low status, dirty and badly paid, an opinion that has stigmatised the industry for many years (CIOB, 2018), but RG Group perceive the industry to be advertised to men as it is proposed to be a masculine and 
strong industry that will build purpose and identity as a man. Another issue that has been identified is that women will not join the construction industry due to family commitments. Meg Munn (2014) described this as indirect discrimination, explaining that women struggle to deal with the responsibilities of a family as well as staying at work within the industry. Due to this, females view this as an infringement when attempting to progress their careers and feel that they are judged by senior management if they get married or have children.

\subsection{What is the industry doing to attract Females to join the industry?}

There are various efforts within the construction industry to reduce the skills deficit by targeting both genders and females individually of all ages. An example of this is The Black Country Children's University. University of Wolverhampton (2018), explains 'as the University of Opportunity, they are committed to raising the aspirations of children within our communities'. Using this initiative it encourages young adults to learn about the construction industry and other sectors within the workplace. This initiative reaches out to many schools and academies in Wolverhampton, Sandwell, Dudley, Walsall and ECMAT (Education Central Multi Academy Trust). The Construction Youth Trust (CYT) (2017) offer short courses that are designed to present the opportunities that exist within the industry. The CYT aims their courses at young people aged between 18-30, who may be unemployed. Athena SWAN (2019) support universities and colleges to build inclusive cultures that build the values of diversity, and resist the barriers for students and employees to progress whilst challenging the unfair practices that disadvantage their peers. Athena SWAN offer bronze, silver and gold accreditations to the educational sectors enabling institution to meet the criteria and aim for gold. Athena SWAN understands that the main diversity issues are age, disability, ethnicity, gender, intersectionality and new protected characteristics such as religion and sexual orientation. Apprenticeships are also a popular method to help reduce the skills deficit as there are many advantages to them, such as the employer being able to apply for funding and having the benefit of training an individual within their company whilst learning the companies model and working methods, and the apprentice has free training earning a salary for his service whilst gaining qualifications. The RICS (2018), are promoting 'degree apprenticeships' which have similar advantages to a regular apprenticeship; however these are aimed at A-level students with the intention of reducing the skills deficit in professional positions such as in quantity surveying and architecture. This enables experienced employees to train apprentices which enables the average age of an aging workforce to be reduced. In 2017 the Government enhanced the apprenticeshipfunding scheme by introducing an apprenticeship levy to companies who had salary outgoings greater than $£ 3$ million (GOV.UK, 2016). The levy is $0.5 \%$ of their salary output; however companies can recover the costs by employing apprentices. The Government took that view that companies needed to employee and train more employees, enabling the individuals to gain qualifications whilst working. Work experience and sandwich courses are also good methods to persuade students that the construction industry could include a career that is suitable for them. Many year 11 school students have the opportunity to gain 1-2 weeks work experience with an 
employer to help decide a career path for when they leave full time education. My World of Work (2019) explain many advantages of work experience and sandwich courses such as; it helps gain an insight in to work; it uses the required skills used within the work place; it develops self-awareness; it helps to understand the links between school subjects and work and it helps the students meet new people. Balfour Beatty (2018), explain that only $13 \%$ of the construction industry is made up of females, however they are encouraging more females to join the sector by raising the profile of their current female employees, campaigning to help females join the industry and using their 'Women In Construction and Engineering' (WICE) awards to promote it. Through this Balfour Beatty expect women's participation to increase to $25 \%$ by 2020. The CITB (2018) have also developed an organisation called Women in Construction (WIC) to help persuade females to join the sector and to help solve the skills shortage. However WIC explained five key objectives to help potential candidates, they are; advice, training, work placements, mentoring and jobs. By completing these objectives the CITB feel that they will improve the following; retention of women in construction, productivity, opportunity to secure work and capacity and skills to implement new policies to attract and retain women. By reviewing these main areas, it enables further research to be reviewed, detail and recommend new methods to reduce the skills deficit, encouraging young adults to join the industry.

\section{Methodology}

A mixture of primary and secondary research was used for this study. Saul McLeod (2017) describes qualitative research as data collected through participant observation and interviews. Therefore within this study interviews were completed consisting of both closed and open questions, enabling the interviewer to extract as much information from the participants as possible. The participants for this study were all students in Universities studying towards their degree in construction related aspects, doing Bachelor of Science (BSc), Master of Science (MSc) and Doctor of Philosophy (Phd) courses containing 6 males and 6 females. This enables the researcher to gain experienced views from both genders and students who are studying different levels of education. Each interview took up to 40 minutes. The questions during the interview were aimed to gain a brief idea of the participant's general knowledge and experience within the built environment and to understand the participants' perception of women in construction. To help find further information about the skills shortages within the construction industry, journals from construction bodies such as the CIOB, the RICS and the CITB, Government and ONS documents have been identified and studies to ensure that research and data has been maximised enabling a full research study has been completed. By using the information gained throughout the literature review and the interviews will enable the researcher to complete the research objectives and conclude the study with a solution to this issue. 


\begin{tabular}{lccc}
\hline \multicolumn{1}{c}{ Challenges } & Combined ranking & Male Ranking & Female Ranking \\
\hline Gaps in Gender Equality & $8 \%$ & $0 \%$ & $17 \%$ \\
Society’s Perspective/Stereotype & $25 \%$ & $33 \%$ & $17 \%$ \\
Lack of Awareness in Opportunities & $8 \%$ & $0 \%$ & $17 \%$ \\
Discrimination and Harassment & $42 \%$ & $50 \%$ & $33 \%$ \\
Family Commitments & $17 \%$ & $17 \%$ & $17 \%$ \\
\hline
\end{tabular}

\section{$4 \quad$ Results and Analysis}

This section summarises the data collected, enabling the researcher to depict and analyse the information provided. Twelve interviews were successfully completed with participants whom were studying towards construction related degrees.

The first question that was asked, was 'What did the students feel are the main challenges to women in the construction industry?' Table 1 displays the results that students felt discrimination and harassment was the highest challenge to women followed by the stereotype of society. This perspective was the view of both genders combined and individually, however the males also felt the stereotype of the industry by the public was a deterrent to females. Males did however have the opposite view to females about gender equality and awareness of the industry.

The participants were then asked a series of open ended questions, requesting their opinion on what they thought females can bring to the construction industry. The first question was how did the participants feel women could benefit the construction industry? Some of the most common answers were greater diversity, new ideas, a different perspective and a solution to the skills shortage. The following question asked the 12 participants what motivated the students to enrol on a construction related course. $25 \%$ of the students explained that they enrolled due to other family members working in the construction industry, other answers included that the construction industry is a popular industry in their homeland and because some of the participants were good with numbers they studied quantity surveying and commercial courses that complemented the academic ability. The next question asked the participants why they felt that women were less likely to be employed within the construction industry. Figure 1 displays the answers that have been categorised, explaining that discrimination and harassment was the answer offered most commonly, however the participants also felt that that females taking maternity leave was also a big factor. 


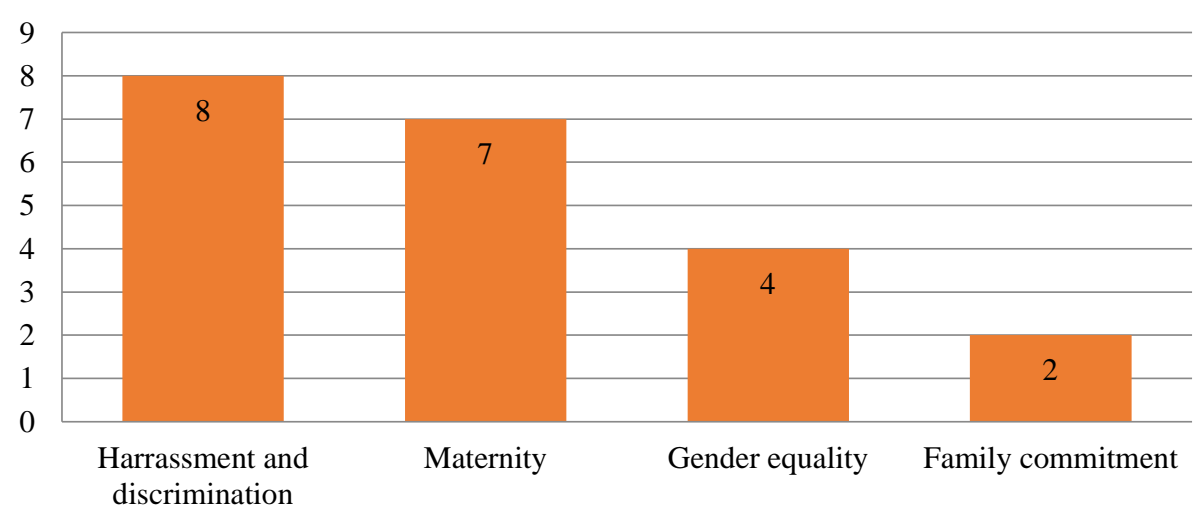

Fig. 1. Factors those are less favorable for women.

The participants were then asked a series of closed questions that were specific to women in construction. The first question was have the participants seen any advertisement toward women in construction. 67\% of the participants answered yes, and then the participants were asked if they knew any women working in construction. $75 \%$ of the participants said yes to this question. This suggests that the construction industry is attempting to promote itself to women. 92\% also felt that the public's perception of the sector feel that it is a male dominated industry and $100 \%$ of the students felt that the awareness of the construction industry needs to be taught to people at a young age. Consequently, the participants were then asked how they felt that women could be further encouraged to join the construction industry.

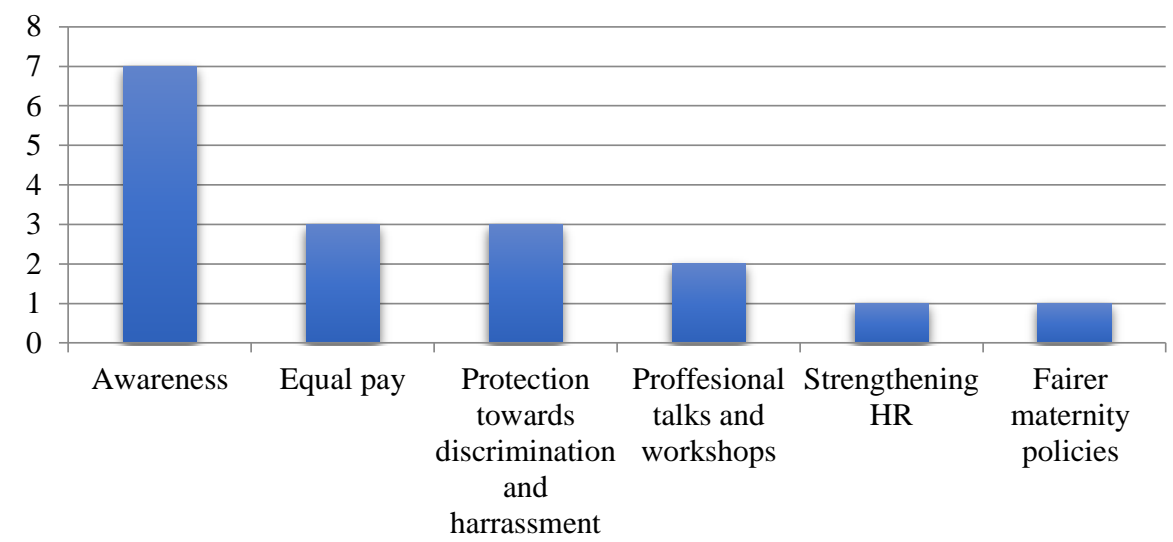

Fig. 2. Factors that encourage women to join the construction industry Figure 2 shows that greater awareness of the industry takes precedence over all of the other suggestions to get more women involved, as 7 of the participants suggested this 
compared to only 3 participants feeling that further support towards equal pay and protection against discrimination is required.

Figure 3 displays the students understanding of Athena SWAN and WISE is poor as only $25 \%$ feel that they have a good understanding of it. Therefore this shows that academic sector is not teaching or expanding their support of Athena SWAN and the aims academia are working towards.

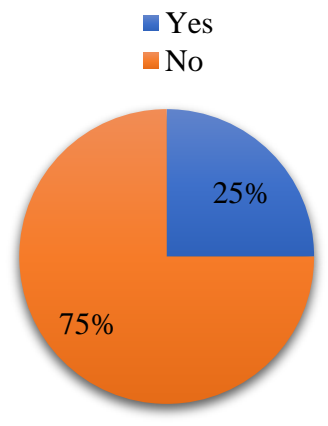

Fig. 3. Students' knowledge of Athena SWAN and WISE

\section{Discussion}

The skills shortage is affecting the construction industry in many ways, but most significantly the UK's housing shortage, aging workforce, rising salary costs and the UK's construction programme to build the required properties. One of the main items that are being reviewed is the difference between males and females working within the construction industry. ONS (2018) explain that only $13 \%$ of construction employees are female. There are many issues that have been identified that explain the reasons for this including discrimination and harassment, equality, awareness, family commitments, maternity and diversity.

RG Group (2017) claim that women will not join the construction industry due the stereotypes that exist, explaining that females feel inferior to men in a male dominated industry and therefore are often drawn to joining other sectors. This proves that the construction industry is poorly marketed as it has been described as low status, dirty and badly paid (CIOB, 2014). This is supported by $75 \%$ of the participants in this study agreeing that harassment and discrimination is a huge factor stopping females joining the industry. However, having been identified by industry professional Matthew Goff (2019), Director of UK operations at Actavo Building Solutions, that there is pay inequality issues with males being paid an extra $45.5 \%$, consequently $25 \%$ of students agreed this is an issue that needs to be resolved. 10 participants confirmed family commitment and 2 participants further confirming maternity legislation as issues for females joining the sector. Meg Munn (2014) confirmed this view explaining that females do get judged, especially if they get 
married or have children. Meg Munn, also confirmed that this is indirect discrimination and women struggled to cope with the pressures of both work and family commitments due to a lack of support from there companies. Although there is not much that can persuade women to change their internal perception of how they feel about coming back to work when starting a family, businesses can do more to show support to working mothers.

The research completed via the literature review and the interviews with current students coincide. Matthew Goff (2019), Director of UK operations at Actavo Building Solutions, firstly admitted that including females within the workforce enables greater diversity and will help achieve greater results across a business. This is supported by many of the students who were interviewed explained that females joining the industry would bring greater diversity, new ideas, a different perspective and a method to reducing the skills shortage. The CITB (2018) also confirmed that by offering females advice, training, mentoring, work placements and jobs it will offer the construction industry a greater skill set and the opportunity for organisations to retain their staff reducing the staff turnover and a reduction in recruitment costs but also the potential to win further work.

The construction industry is attempting to improve the awareness of the construction industry for both males and females. 58\% of participants suggested that greater awareness needs to be improved within the construction industry to enable further people to join the sector. The University of Wolverhampton is supporting the Black Country Children's University, encouraging young adults to join the industry. Balfour Beatty are one of many companies encouraging women in construction through their 'Women in Construction and Engineering' awards, and therefore expect women's construction participation to increase by $25 \%$ by 2020 . The participants also explained that workshops, work experience and construction talks would enable prospective construction workers to gain a greater understanding of the sector. The Construction Youth Trust (CYT) (2017) promotes short courses that are designed to help 18-30 year olds get back into employment, supported by Meg Munn (2014) confirmed that contractors should offer work experience to females, and explaining that women should contact contractors to gain a greater understanding of the industry and feminist Kimberle Crenshaw (2016) claims that there must be support against sectionality.

The students were asked if they had seen any advertisement promoting to the industry to females. $66.66 \%$ answered yes, however other research suggests the construction industry is low status, dirty and badly paid. Therefore this shows effort needs to be made on specific campaigns enabling females to learn more about the industry giving them the opportunity to display the talents they have and having a major input in to the construction sector. Jon Henley of The Guardian (2018) announced the Icelandic Government have now made it a legal requirement for both males and females to receive equal pay. The UK government must now reflect upon the legal changes within Iceland and support those changes reviewing the pay equality UK legislation. The UK Government should also review the Swedish policies surrounding the maternity policy as Libby Kane of Business Insider (2018) revealed that Sweden's maternity and paternity policy is one of the best in the world as males 
and females are allowed to share 480 days earning at least $80 \%$ of their salaries. By supporting these policies, it will encourage females to join the construction industry by reducing the discrimination.

\section{Conclusion}

The scope of this study was to review what the limitations are that stop women joining the construction industry, but also raise awareness of the benefits of the industry from a student's perception and therefore a literature review of the current market research was completed to find out what the impact of the skills shortage was, the obstructions stopping females joining the industry and how women are a benefit to the sector. Therefore using this information enabled qualitative research to be completed, however one limitation was that only 12 students were interviewed and interviews could have been conducted with women working in the industry to gain an incite of their experiences.

The results from the collected data show that the construction industry displays limitations that are deterring women from the industry such as harassment and discrimination, awareness, equality, and family commitment. However research also suggests that females also have many attributes that could benefit the construction sector such as bringing greater diversity, new ideas, a different perspective and a method to solve the skills shortage. There are many initiatives that are attempting to solve the skills shortage such as teaching students from a school age, an idea that the participants promoted and are supported by the University of Wolverhampton. There are also other organisations such as the Construction Youth Trust, Athena SWAN, Princes Trust and the Lighthouse Club that promote the industry to the public and construction bodies such as the CIOB, CITB and the RICS whom develop and promote programmes. The industry also needs to prove that it has removed the poor stigmas, by removing the harassment and discrimination issues that surround the sector. This must be supported by a culture change, teaching young adults that the sector supports both genders, enabling females to have raise families as well as the opportunity to enhance their career. Research also suggests that there other nations support legislation such are pay equality and maternity leave and pay and therefore it is suggested the UK government should review their policies. Large construction contractors similar to Balfour Beatty must publicly challenge themselves to improve the employment conditions females are working in and be supported by improved government legislation and construction bodies such as the CIOB, CITB and the RICS to remarket the sector teaching young adults from a school age about what the construction industry involves enabling males and females to have a greater input into the sector. 


\section{References}

1. Balfour Beatty plc.: Inspiring Change: Attracting women into construction. https://www.balfourbeatty.com/how-we-work/public-policy/inspiring-change-attractingwomen-into-construction, last accessed 2019/03/11, (2018).

2. Business Insider.: Sweden is apparently full of 'latte dads' carrying toddlers - and it's a sign of critical social change, https://www.businessinsider.com/sweden-maternity-leavepaternity-leave-policies-latte-dads-2018-4?r=US\&IR=T, last accessed 2019/03/24 (2018).

3. Changing The Face of Construction, https://www.citb.co.uk/documents/funding/social_return_on_investment_for_women_into _construction_oct2018_report.pdf, last accessed 2019/03/17 (2018).

4. Construction Enquirer Homepage, Skills shortages see construction wages rise 6\%, http://www.constructionenquirer.com/2016/01/14/skills-shortages-see-construction-wagesrise-6, last accessed 2019/03/11 (2018).

5. CIOB.: Inspiring the next generation of construction professionals, https://www.ciob.org/campaigns/inspiring-next-generation-construction-professionals, last accessed 2019/03/18 (2019).

6. Constructionyouth.org.uk.: Budding Brunels | Construction Youth Trust, http://www.constructionyouth.org.uk/budding-brunels last accessed 2019/03/11(2017).

7. Equality Challenge Unit Homepage - Equality Challenge Unit, https://www.ecu.ac.uk, last accessed 2019/04/07 (2019).

8. Goff, M.: Why the construction industry needs to embrace diversity - Actavo, https://actavo.com/latest-news/construction-industry-needs-embrace-diversity, last accessed 2019/03/11 (2019).

9. GOV.UK.: Apprenticeship funding: how it works, https://www.gov.uk/government/publications/apprenticeship-levy-how-it-willwork/apprenticeship-levy-how-it-will-work, last accessed 2019/04/07 (2016).

10. GOV.UK.: Police workforce open data tables, https://www.gov.uk/government/statistics/police-workforce-open-data-tables, last accessed 2019/03/18 (2018).

11. Henley, J.: 'Equality won't happen by itself': how Iceland got tough on gender pay gap. The Guardian, https://www.theguardian.com/world/2018/feb/20/iceland-equal-pay-law-gendergap-women-jobs-equality, last accessed 2019/03/23 (2018).

12. Kollewe, J.: Hard hat revolution: women targeted to fill vacancies as housebuilding revives. The Guardian, https://www.theguardian.com/business/2014/dec/30/womenworking-construction-industry-housing-boom-rise, last accessed 2019/03/18 (2014).

13. Mcleod, S.: Qualitative vs Quantitative Research | Simply Psychology, https://www.simplypsychology.org/qualitative-quantitative.html, last accessed 2019/03/11 (2017).

14. Munn, M.: Building the future: Women in construction, http://www.designengineerconstruct.com/pdfs/building-the-future-women-inconstruction.pdf, last accessed 2019/03/16 (2014).

15. My World of Work Homepage. Work experience, https://www.myworldofwork.co.uk/work-experience-0, last accessed 2019/04/07 (2019).

16. Office for National Statistics Homepage. UK Workforce Jobs SA : F Construction, https://www.ons.gov.uk/employmentandlabourmarket/peopleinwork/employmentandempl oyeetypes/timeseries/jws2/lms, last accessed 2019/03/18 (2017). 
409

17. Prior, G.: Construction to create 168,500 new jobs despite Brexit | Construction Enquirer, https://www.constructionenquirer.com/2019/02/25/construction-to-create-168500-newjobs-despite-brexit, last accessed 2019/03/11 (2019).

18. Radford, S.: Construction - Shortage in the Workforce - Blog. Ai Solutions Ltd, https://www.aisolutions.co.uk/Blog/2017/01/construction-shortage-in-workforce, last accessed 2019/03/11 (2017).

19. RG Group.: Why is there a lack of women in the construction industry? - RG Group, http://rg-group.co.uk/why-is-there-a-lack-of-women-in-the-construction-industry, last accessed 2019/03/11 (2017).

20. RICS Recruit.: How Diversity Helps the Workplace, https://www.ricsrecruit.com/article/how-diversity-helps-the-workplace/, last accessed 2019/03/23 (2018).

21. Schouten, C.: Women in construction: what do the numbers say? Construction News, https://www.constructionnews.co.uk/data/industry-barometer/women-in-constructionwhat-do-the-numbers-say/10017870.article, last accessed 2017/03/18 (2017).

22. Scotland.police.uk Homepage, Police Scotland encouraging new female recruits - Police Scotland, https://www.scotland.police.uk/whats-happening/news/2017/january/policescotland-encouraging-new-female-recruits, last accessed 2019/03/18 (2017).

23. Theconstructionindex.co.uk Homepage, Skill shortages are pushing up construction wages, https://www.theconstructionindex.co.uk/news/view/skill-shortages-are-pushing-upconstruction-wages, last accessed 2018/07/14, (2016).

24. The Urgency of Intersectionality.: [video] TED Talks. (2016).

25. University of Wolverhampton Homepage, Childrens University, https://www.wlv.ac.uk/about-us/schools-and-colleges/programmes/childrens-university, last accessed 2019/03/11, (2018). 